\title{
Tubular Transport Mechanisms of Quinapril and Quinaprilat in the Isolated Perfused Rat Kidney: Effect of Organic Anions and Cations
}

\author{
Alan R. Kugler, ${ }^{1,2}$ Stephen C. Olson, ${ }^{1}$ and David E. Smith ${ }^{2,3}$ \\ Received August 11, 1995-Final Stepember 17, 1996
}

\begin{abstract}
The clearance mechanisms of quinapril and quinaprilat were probed using an isolated perfused rat kidney model. Sixty-four experiments were performed with drug in the absence and presence of classic inhibitors of the organic acid (i.e., probenecid and p-aminohippurate) and organic base (i.e., tetraethylammonium and quinine) transport systems of the proximal tubule. Initial perfusate concentrations of quinapril and quinaprilat were approximately $2.36 \mu \mathrm{M}$ (or $1000 \mathrm{ng} / \mathrm{ml}$ ), and transport inhibitors were coperfused at 100-10,000 times the drugs' initial $\mu M$ concentrations. Quinapril and quinaprilat concentrations were determined in perfusate, urine, and perfusate ultrafiltrate using a reversed-phase HPLC procedure with radiochemical detection, coupled to liquid scintillation spectrometry. Perfusate protein binding was determined using an ultrafiltration method at $37^{\circ} \mathrm{C}$. Overall, the clearance ratios of quinapril (total renal clearance divided by $\mathrm{fu} \cdot \mathrm{GFR}$ ) and quinaprilat (urinary clearance divided by $\mathrm{fu}$ - GFR) were significantly reduced, and in a dose-dependent manner, by the coperfusion of organic acids but not organic bases. The data demonstrate that the organic anionic secretory system is the primary mechanism by which quinapril and quinaprilat are transported into and across renal proximal cells.
\end{abstract}

KEY WORDS: quinapril; quinaprilat; isolated perfused rat kidney; organic anions; organic cations; transport; metabolism.

\section{INTRODUCTION}

Angiotensin converting enzyme (ACE) inhibitors have become established therapy in two of the most common cardiac pathologies, namely, hypertension and congestive heart failure (1-4). ACE inhibitors may also

\footnotetext{
This work was supported in part by a gift from Parke-Davis Pharmaceutical Research, Division of Warner-Lambert Company and by National Institutes of Health Grant R01 GM35498.

${ }^{\mathrm{I}}$ Department of Pharmacokinetics and Drug Metabolism, Parke-Davis Pharmaceutical Research, Division of Warner-Lambert Company, Ann Arbor, Michigan 48106-1047.

${ }^{2}$ College of Pharmacy and Upjohn Center for Clinical Pharmacology, 3705 Upjohn Center, The University of Michigan, Ann Arbor, Michigan 48109-0504.

${ }^{3}$ To whom correspondence should be addressed.
} 
be useful in patients with diabetic nephropathy since they do not affect glucose or lipid metabolism while reducing renal vascular resistance and renal perfusion pressure (5). Although much is known about their mechanism of action and hemodynamic effects, much less is known about the renal disposition of ACE inhibitors. In particular, detailed aspects of their renal tubular transport mechanisms have yet to be fully elucidated. This may be important because cardiorenal homeostasis depends not only upon systemic effects on the renin-angiotensin-aldosterone (RAA) system but also upon local effects on the RAA system in kidney. Further, intrarenal metabolism of ACE inhibitor prodrugs to their pharmacologically active metabolites may contribute to their concentration-effect relationship.

Previous studies in the isolated perfused rat kidney (rat IPK) have suggested that quinapril (Accupril ${ }^{\circledR}$, Parke-Davis) and quinaprilat are both actively transported by proximal tubular cells of the kidney (6). However, in the case of quinapril, the contribution of an active secretory process to its overall renal elimination was significantly complicated by intrarenal metabolism of drug to its de-esterified active form quinaprilat. Thus, of the total renal clearance for quinapril (i.e., excretory and metabolic), less than $0.1 \%$ was cleared as unchanged drug and over $99 \%$ was cleared as intrarenally formed quinaprilat. Notwithstanding this complication, the clearance ratio of quinapril was 41.0 (using the total renal clearance method; $\left.C L_{\mathrm{I}}[f u \cdot G F R]\right)$, a value indicative of substantial net transport across the basolateral membrane of proximal tubular cells (6). Still, a precise mechanistic basis for quinapril and quinaprilat's renal tubular transport needs to be established.

With this in mind, and given the fact that quinapril and quinaprilat are amphoteric compounds, the renal tubular handling of these drug species was further explored in the rat IPK using classic inhibitors of the organic acid and base transport systems of the proximal tubule.

\section{MATERIALS AND METHOD}

\section{Animals}

Male Sprague-Dawley rats (body weight, 324-464 g) were used as kidney donors for the rat IPK preparations. All animals were allowed free access to food and water before experimentation. They were anesthetized with sodium pentobarbital $(64.8 \mu \mathrm{g} / \mathrm{g}$ body weight, intraperitoneal) prior to surgery.

\section{Surgical Procedure}

The surgical approach adopted for the rat IPK system was based on the methods of Nishiitsutsuji-Uwo et al. (7) and Bowman (8) with minor modifications (6). 


\section{Perfusate Composition}

The kidney was perfused with a medium containing $6 \%$ bovine serum albumin, $0.1 \%$ glucose, and a mixture of $20 \mathrm{~L}$-amino acids (9) in KrebsHenseleit bicarbonate buffer (10). This perfusing medium was aerated with humidified $\mathrm{O}_{2}: \mathrm{CO}_{2}(95: 5)$, and the $\mathrm{pH}$ was maintained throughout the experiment at 7.4. The perfusate volume was $100 \mathrm{ml}$. A detailed description of the perfusion apparatus has been reported previously (6).

\section{Chemicals}

${ }^{3} \mathrm{H}$-Quinapril and ${ }^{3} \mathrm{H}$-quinaprilat were obtained from Amersham Buchler GmbH \& Co. KG, Braunschweig, Germany. Radiochemical purity of both compounds was determined to be $>98 \%$ by HPLC. Specific activities were 20.1 and $22.2 \mathrm{mCi} / \mathrm{mg}$ for ${ }^{3} \mathrm{H}$-quinapril and ${ }^{3} \mathrm{H}$-quinaprilat, respectively. Unlabeled quinapril (hydrochloride) and quinaprilat (monohydrate) were obtained from Parke-Davis, Ann Arbor, MI. Purity of both compounds was determined to be $\geq 99 \%$ by HPLC. ${ }^{14} \mathrm{C}$-Inulin (specific activity $2.5 \mu \mathrm{Ci}$ / $\mathrm{mg}$ ) was obtained from ICN Biochemicals Inc., Irvine, CA, and various transport inhibitors (probenecid, p-aminohippurate, tetraethylammonium, and quinine) were purchased from Sigma Chemical Co., St. Louis, MO. For the IPK studies, radiolabeled and unlabeled ACE inhibitors were combined for appropriate dilution, their solvents evaporated under a gentle stream of nitrogen, and reconstituted with a small volume of blank perfusate. Inulin was dissolved in distilled water $(16.7 \mu \mathrm{Ci} / \mathrm{ml})$ and the transport inhibitors were dissoved in a small volume of blank perfusate.

\section{Experimental Protocol}

Once the kidney had been placed in the Plexiglas chamber, a 15-min equilibration period was allowed for stabilization of the preparation. ${ }^{3} \mathrm{H}$ Quinapril or ${ }^{3} \mathrm{H}$-quinaprilat ( \pm inhibitors) and/or ${ }^{14} \mathrm{C}$-inulin $(2.5 \mu \mathrm{Ci})$ were introduced into the reservoir as bolus doses (considered time zero), and an additional $15 \mathrm{~min}$ were then allowed for drug disposition and hemodynamic stability to occur. The subsequent time $(15-105 \mathrm{~min})$ was divided into nine 10-min urine collection periods for the measurement of kidney function and urinary clearance parameters. The urine volume was measured, and its $\mathrm{pH}$ was determined immediately. Perfusate $(1.5 \mathrm{ml})$ was sampled at the midpoint of each clearance interval. A 10-min perfusate sample was also collected during the $0-15$ minute postbolus equilibration period. This additional sample was used for the calculation of drug disposition parameters only, in which $0-t$ or $0-\infty$ time data were required (e.g., $A U C$ ). Losses in perfusate and urine because of sampling were minimized by isovolumetric replacement 
with blank perfusate and buffer, respectively. All samples were frozen at $\leq-70^{\circ} \mathrm{C}$ until subsequent analysis.

Sixty-four rat IPK experiments were performed with quinapril or quinaprilat in the absence and presence of inhibitors of the organic acid (i.e., probenecid and p-aminohippurate) and organic base (i.e., tetraethylammonium and quinine) transport systems of the proximal tubule. Quinapril or quinaprilat was dosed at $200 \mu \mathrm{Ci}$ (specific activity of $2.0 \mu \mathrm{Ci} / \mu \mathrm{g}$ after approximate $10 \times$ dilution of the original material) so that initial perfusate concentrations approximated $2.36 \mu \mathrm{M}$ (or $1000 \mathrm{ng} / \mathrm{ml}$ ). Transport inhibitors were coperfused at $100-10,000$ times the drugs' initial $\mu \mathrm{M}$ concentrations. Inhibitor doses were first tested at the $1000 \times \mu \mathrm{M}$ level; subsequent doses were determined according to the initial extent of inhibition or detrimental effect on kidney function.

\section{Analytical}

${ }^{3} \mathrm{H}$-Quinapril and ${ }^{3} \mathrm{H}$-quinaprilat concentrations were determined in perfusate, urine, and perfusate ultrafiltrate using a reversed-phase HPLC procedure with radiochemical detection (11). ${ }^{14} \mathrm{C}$-Inulin concentrations were determined by dual-label scintillation spectrometry, glucose by an enzymatic method, and sodium by flame photometry, as discussed previously (6). Additionally, for IPK studies in which quinaprilat was coperfused with p-aminohippurate (at $1000 \times$ and $10,000 \times \mu \mathrm{M}$ ), perfusate samples containing $\mathrm{p}$-aminohippurate were assayed using a reversed-phase HPLC procedure with UV detection (12).

The protein binding of quinapril and quinaprilat was determined by ultrafiltration at $37^{\circ} \mathrm{C}$. The unbound fraction $(f u)$ in perfusate samples, expressed as a percentage, was calculated as the perfusate ultrafiltrate drug concentration $\times 100$ divided by the perfusate drug concentration.

\section{Data Analysis}

Functionality of the rat IPK was assessed primarily by measuring glomerular filtration rate $(G F R)$, the fractional excretion of glucose $\left(F E_{\text {glucose }}\right)$, and the fractional excretion of sodium $\left(F E_{\text {sodium }}\right)$. The renal clearance of inulin was taken to represent GFR.

Given the significant metabolic component of quinapril elimination in the rat IPK (6), the drug's total renal clearance is represented by the sum of excretory and metabolic pathways (i.e., $C L_{\mathrm{r}}=C L_{\mathrm{e}}+C L_{\mathrm{m}}$ ). As such, the total renal clearance of quinapril was determined experimentally as

$$
C L_{\mathrm{r}}=\operatorname{Dose} / A U C_{0-\infty}
$$


where $A U C_{0-\infty}$ is the area under the perfusate drug concentration-time curve from time zero to infinity. $A U C_{0-\infty}$ values were determined using the log-trapezoidal rule for experimental data and extrapolated to infinity using $C p_{\text {last }} / \lambda z$, where $\lambda z$ is the negative of the log-linear terminal slope of quinapril's perfusate concentration vs. time profile. The clearance ratio of quinapril (CR; using the total renal clearance method) was then calculated as

$$
C R=C L_{\mathrm{r}} /(f u \cdot G F R)
$$

The urinary clearance of quinapril was also calculated for each urinary collection period as

$$
C L_{\mathrm{e}}=U \cdot V / C p_{\text {mid }}
$$

where $U$ is the concentration of quinapril in urine, $C p_{\text {mid }}$ is its midpoint perfusate concentration, and $V$ is the urinary flow rate. And finally, the metabolic clearance of quinapril was calculated as

$$
C L_{\mathrm{m}}=C L_{\mathrm{r}}-C L_{\mathrm{e}}
$$

The urinary clearance of quinaprilat (after administration of quinapril or quinaprilat) was calculated for each urinary collection period as

$$
C L_{\mathrm{e}}=U \cdot V / C p_{\text {mid }}
$$

where $U$ is the concentration of quinaprilat in urine, $C p_{\text {mid }}$ is its midpoint perfusate concentration, and $V$ is the urinary flow rate. The clearance ratio of quinaprilat ( $C R$; using the urinary clearance method) was then calculated as

$$
C R=C L_{\mathrm{e}} /(f u \cdot G F R)
$$

It should be appreciated that after quinaprilat dosing in rat IPK experiments, the urinary clearance and total renal clearance of quinaprilat are equivalent since the preformed metabolite is removed solely by renal excretion (i.e., $\left.C L_{\mathrm{m}}=0\right)(6)$.

Data are reported as the mean $\pm \mathrm{SD}$, unless otherwise indicated. To test for statistically significant differences among treatments for a given parameter, one-way analysis of variance (ANOVA) was performed. When the $F$ ratio showed that there were significant differences among treatments, the Student-Newman-Keuls method of multiple comparisons was used to determine which treatments differ. All statistical computations were performed using SAS 5.18 software (SAS Institute; Cary, NC) and a significance level of $\alpha=0.05$. 


\section{RESULTS}

\section{Quinapril Administration}

\section{Physiologic Function}

Perfusion pressure, perfusate flow rate, $G F R, F E_{\text {glucose }}, F E_{\text {sodium }}$, urine flow rate, and urine $\mathrm{pH}$ were evaluated as indices of renal functionality in rat IPK experiments (Table I). Following quinapril administration, there were no significant differences in renal function for quinapril plus inhibitor treatments vs. quinapril alone, with the exception of $F E_{\text {sodium }}$ and urine flow rate in those experiments with $\mathrm{p}$-aminohippurate. Although the reasons for these increased values is unclear, it is possible that p-aminohippurate may be acting as an osmotic diuretic, thereby promoting a greater output of sodium and urine. Overall, physiologic parameters were within the normal range of values for this technique (13-18), and were stable for the duration of each experiment.

\section{Disposition of Quinapril}

In the absence of transport inhibitors, quinapril is rapidly eliminated from the perfusate of IPK studies (6). However, when coperfused with organic acid inhibitors, the log-linear disappearance of quinapril from perfusate was markedly reduced (Fig. 1). In fact, it appears that the elimination of quinapril was virtually shut down by probenecid at the $1,000 \times \mu \mathrm{M}$ concentration. These changes are due to a substantial and dose-dependent reduction in the total renal clearance of quinapril in the presence of probenecid and p-aminohippurate (Table II); no change was observed in the total renal clearance of quinapril when coperfused with tetraethylammonium or quinine. Similar reductions were observed in the metabolic clearance of quinapril ( \pm inhibitors) since the drug is almost completely metabolized. The urinary clearance of quinapril was negligible ( $\leq 3.2 \%$ for all treatment groups) and due its substantial metabolism within the kidney, this parameter is a poor indicator of renal tubular transport mechanisms (6). As a result, clearance ratio $(C R)$ of quinapril was determined using the total renal clearance method. In this form, calculation of $C R$ is independent of the site of intrarenal metabolism and represents net transport across the basolateral membrane. As shown in Table II, the clearance ratio of quinapril was substantially reduced by probenecid and in a dose-dependent manner (24.7fold at $1000 \times \mu \mathrm{M})$. A similar reduction in quinapril clearance ratio was observed with p-aminohippurate. Thus, perfusate concentrations of quinaprilat were decreased since quinapril entry into proximal tubular cells was blocked along with its subsequent intrarenal metabolism (Fig. 2). In contrast, tetraethylammonium and quinine caused an approximate $21-33 \%$ increase in the clearance ratio of quinapril. 


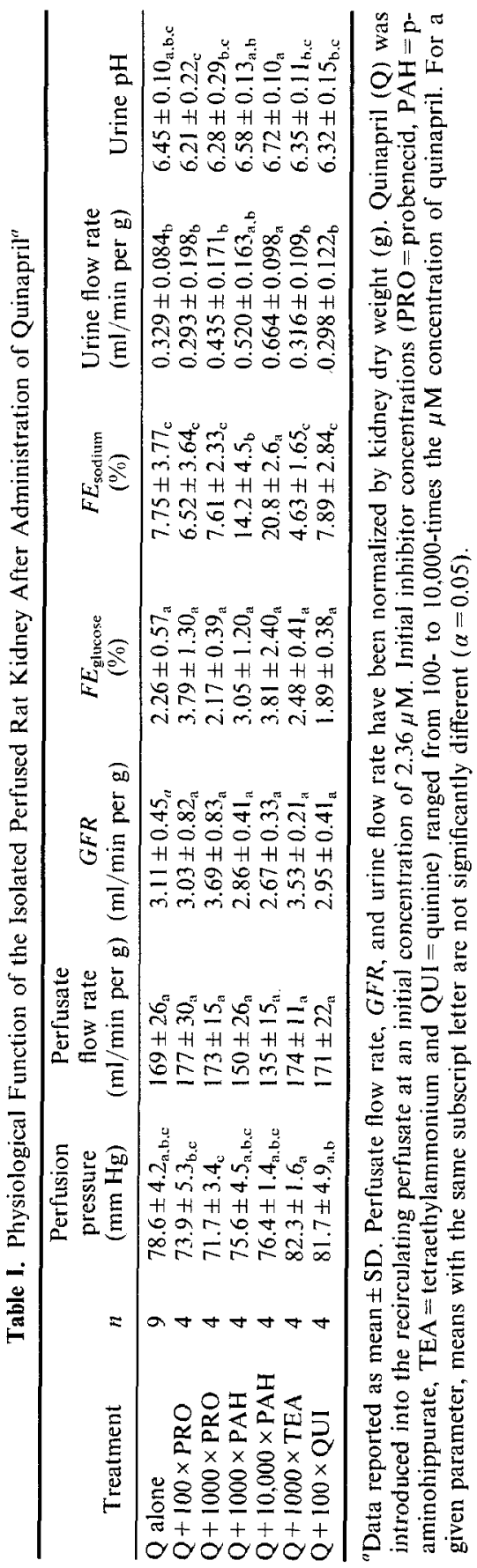




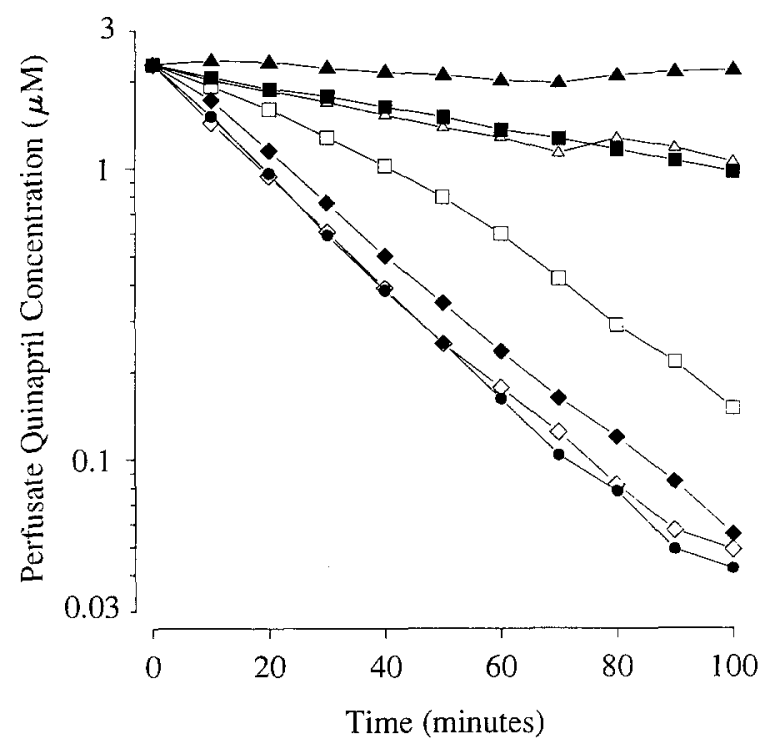

Fig. 1. Perfusate concentration-time curves for quinapril in the rat IPK after administration of quinapril $(2.36 \mu \mathrm{M})$ alone $(\bullet$, $n=9$ ), or when coperfused with probenecid at $100 \times \mu \mathrm{M}$ $(\Delta, n=4)$, probenecid at $1000 \times \mu \mathrm{M}(\boldsymbol{\Lambda}, n=4), \mathrm{p}$-aminohippurate at $1000 \times \mu \mathrm{M} \quad(\square, n=4)$, p-aminohippurate at $10,000 \times \mu \mathrm{M}(\mathbf{\square}, n=4)$, tetraethylammonium at $1000 \times \mu \mathrm{M}$ $(\diamond, n=4)$, and quinine at $100 \times \mu \mathrm{M}(\diamond, n=4)$. For the sake of clarity, only mean data are shown.

\section{Disposition of Quinaprilat}

A time-dependent change was observed in the clearance ratio of quinaprilat (generated metabolite) after dosing quinapril alone and in the presence of inhibitors (Fig. 3). This time dependence is predicted by Eq. (5), and reflects the fact that intrarenally formed quinaprilat either undergoes excretion or effluxes back into the recirculating perfusate for subsequent reentry into the kidney, or both. As a result, quinaprilat excretion is dominated initially by quinapril to quinaprilat conversion and at later times by the urinary clearance of reabsorbed metabolite. The clearance ratio of preformed metabolite simply reflects its urinary clearance. Thus, the clearance ratios of intrarenally formed and preformed quinaprilat will ultimately be the same once quinapril has been effectively removed from the system (6). Interestingly, the clearance ratios of intrarenally formed quinaprilat were consistently lower in the p-aminohippurate as opposed to other treatment groups including probenecid (Fig. 3). 


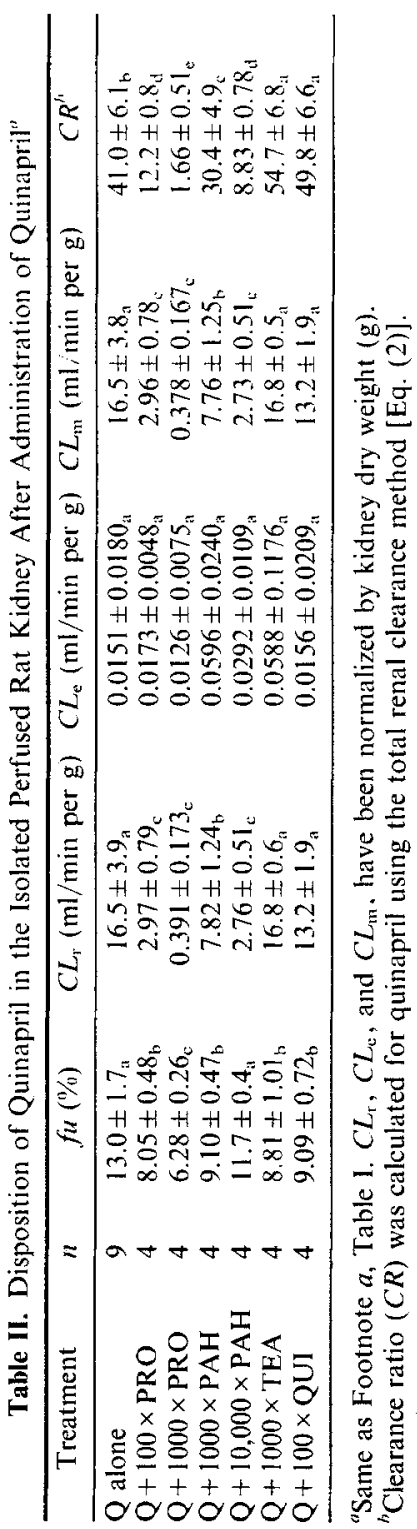




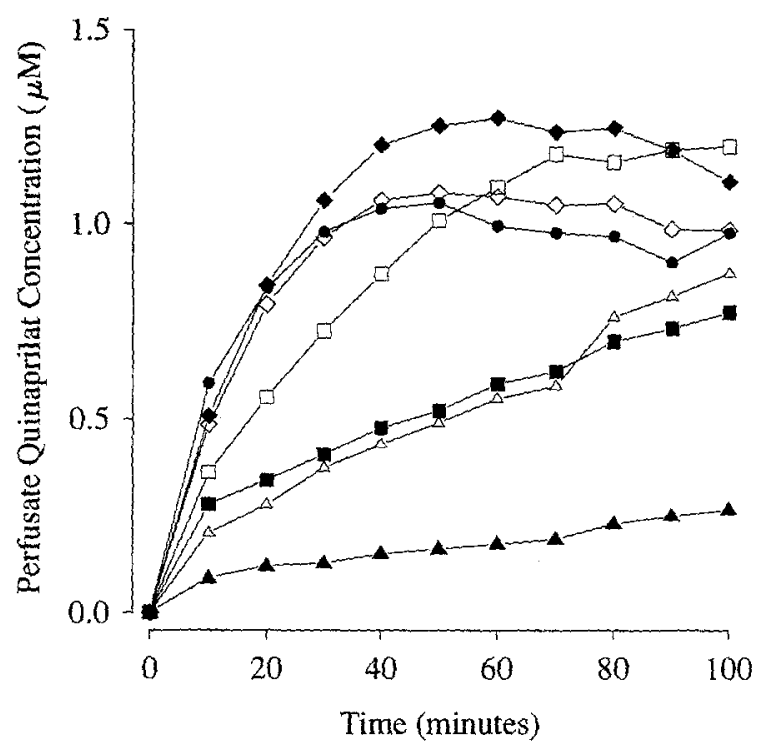

Fig. 2. Perfusate concentration-time curves for quinaprilat in the rat IPK after administration of quinapril $(2.36 \mu \mathrm{M})$ alone (9, $n=9$ ), or when coperfused with probenecid at $100 \times \mu \mathrm{M}$ $(\Delta, n=4)$, probenecid at $1000 \times \mu \mathrm{M}(\Lambda, n=4)$, p-aminohippurate at $1000 \times \mu \mathrm{M} \quad(\square, n=4)$, p-aminohippurate at $10,000 \times \mu \mathrm{M}(\mathbf{\square}, n=4)$, tetraethylammonium at $1000 \times \mu \mathrm{M}$ $(0, n=4)$, and quinine at $100 \times \mu \mathrm{M}(\Lambda, n=4)$. For the sake of clarity, only mean data are shown.

\section{Quinaprilat Administration}

\section{Physiologic Function}

Following quinaprilat administration, there were no significant differences in renal function for quinaprilat plus inhibitor treatments vs. quinaprilat alone, with one exception (Table III). $F E_{\text {sodium }}$ and urine flow rate were significantly greater when quinaprilat was coperfused with high dose $p$-aminohippurate $(10,000 \times \mu \mathrm{M})$. This finding is similar to that described earlier for quinapril $\pm \mathrm{p}$-aminohippurate and probably reflects an osmotic diuretic effect. Physiologic parameters were within the normal range of values for this technique $(13-18)$, and were stable for the duration of each experiment.

\section{Disposition of Quinaprilat}

Quinaprilat is slowly eliminated from the perfusate of IPK preparations (6) and, as a result, its renal clearance is more accurately determined as urinary excretion rate divided by the corresponding midpoint perfusate 


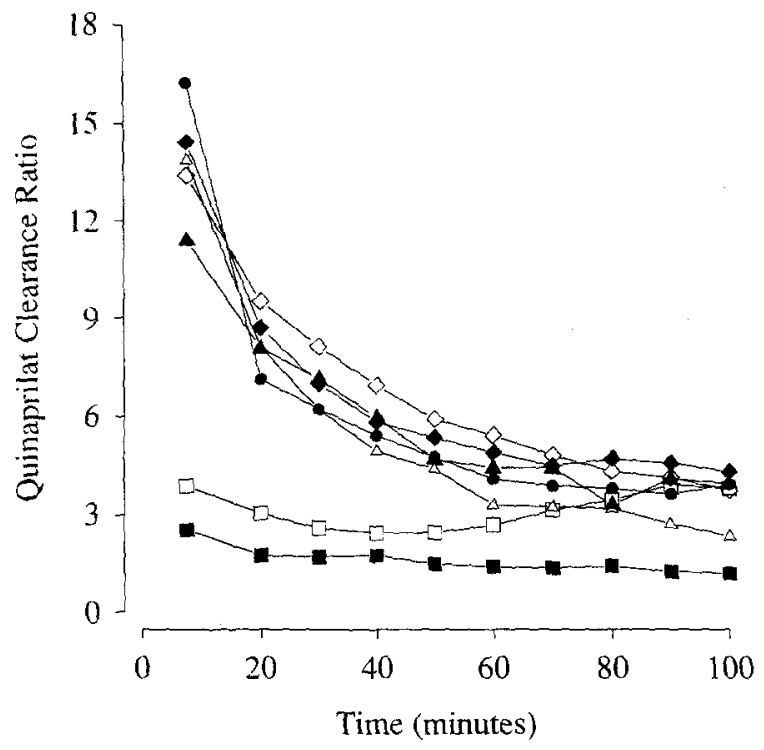

Fig. 3. Clearance ratio-time curves for quinaprilat in the rat IPK after administration of quinapril $(2.36 \mu \mathrm{M})$ alone (e, $n=9)$, or when coperfused with probenecid at $100 \times \mu \mathrm{M}(\triangle$, $n=4)$. probenecid at $1000 \times \mu \mathrm{M}(\Delta, n=4)$, p-aminohippurate at $1000 \times \mu \mathrm{M}(\square, n=4)$, p-aminohippurate at $10,000 \times \mu \mathrm{M}(\boldsymbol{\square}$, $n=4)$, tetraethylammonium at $1000 \times \mu \mathrm{M}(\diamond, n=4)$, and quinine at $100 \times \mu \mathrm{M}(\diamond, n=4)$. For the sake of clarity, only mean data are shown.

concentration. A slow disappearance rate was also observed in these IPK studies (quinaprilat \pm inhibitors) following an initial distribution phase of about $15 \mathrm{~min}$ (Fig. 4). As shown in Table IV, the urinary clearance of preformed quinaprilat was significantly reduced by organic acid but not organic base inhibitors. When differences in protein binding and GFR were taken into account, the clearance ratio of preformed quinaprilat was still reduced in a dose-dependent manner by probenecid ( 5.7 -fold at $1000 \times \mu \mathrm{M}$ ) and by p-aminohippurate $(4,4$-fold at $10,000 \times \mu \mathrm{M})$. In contrast, there was no difference in quinaprilat's clearance ratio when coperfused with either tetraethylammonium or quinine.

\section{Protein Binding}

On average, the fraction unbound was $6.28-13.0 \%$ for quinapril (after dosing quinapril) and 17.0-24.9\% for quinaprilat (after dosing quinaprilat). For all IPK studies, the protein binding of both drug species was linear. 


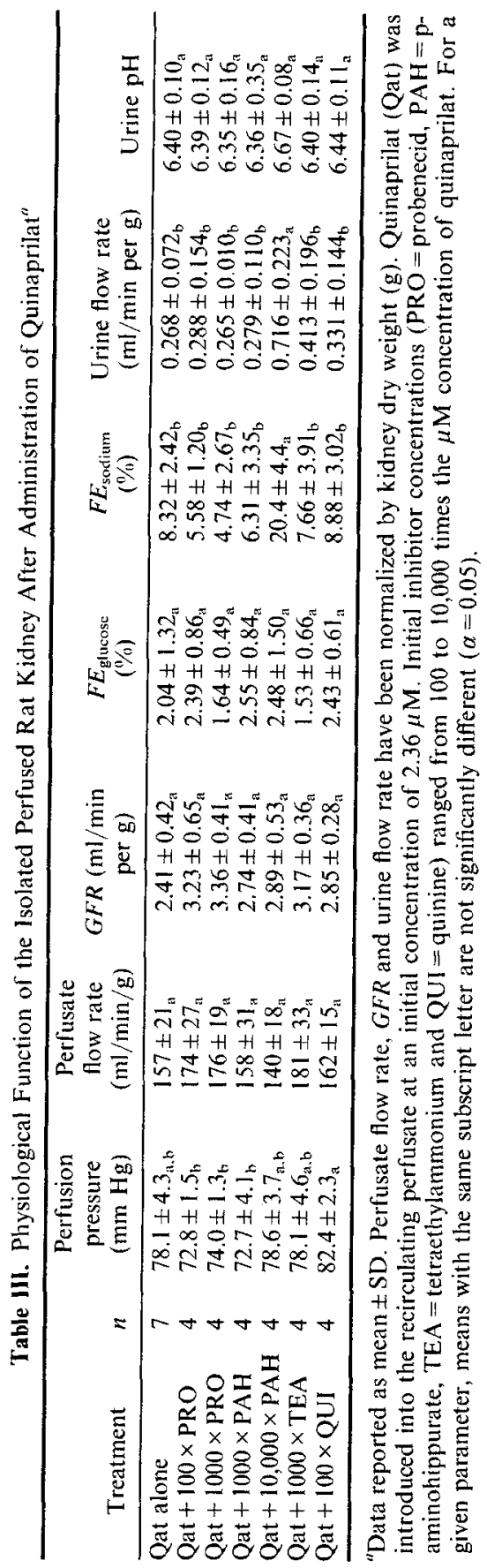




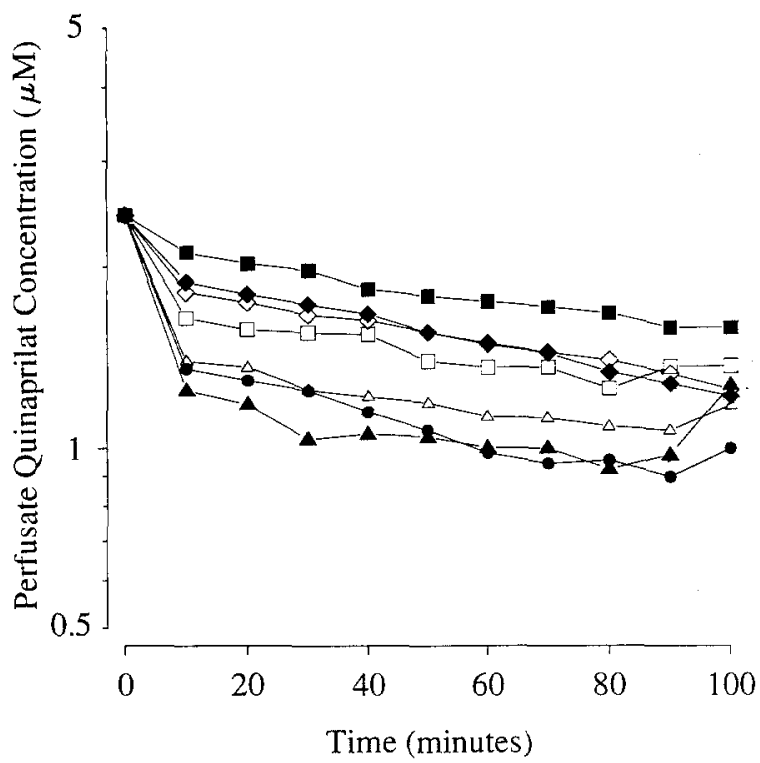

Fig. 4. Perfusate concentration-time curves for quinaprilat in the rat IPK after administration of quinaprilat $(2.36 \mu \mathrm{M})$ alone $(\bullet, n=7)$, or when coperfused with probenecid at $100 \times \mu \mathrm{M}$ $(\triangle, n=4)$, probenecid at $1000 \times \mu \mathrm{M}(\boldsymbol{\Delta}, n=4)$, p-aminohippurate at $1000 \times \mu \mathrm{M} \quad(\square, n=4)$, p-aminohippurate at $10,000 \times \mu \mathrm{M}(\boldsymbol{\square}, n=4)$, tetraethylammonium at $1000 \times \mu \mathrm{M}$ $(\diamond, n=4)$, and quinine at $100 \times \mu \mathrm{M}(\bullet, n=4)$. For the sake of clarity, only mean data are shown.

Table IV. Disposition of Quinaprilat in the Isolated Perfused Rat Kidney After Administration of Quinaprilat ${ }^{a}$

\begin{tabular}{lcccc}
\hline Treatment & $n$ & $f u(\%)$ & $C L_{\mathrm{e}}(\mathrm{ml} / \mathrm{min} / \mathrm{g})$ & $C R^{b}$ \\
\hline Qat alone & 7 & $23.8 \pm 1.6_{\mathrm{a}}$ & $2.18 \pm 0.54_{\mathrm{a}}$ & $3.85 \pm 0.73_{\mathrm{a}}$ \\
Qat $+100 \times$ PRO & 4 & $24.9 \pm 2.5_{\mathrm{a}}$ & $0.903 \pm 0.170_{\mathrm{c}}$ & $1.13 \pm 0.09_{\mathrm{c}}$ \\
Qat $+1000 \times$ PRO & 4 & $22.6 \pm 1.3_{\mathrm{a}}$ & $0.516 \pm 0.059_{\mathrm{c}}$ & $0.681 \pm 0.055_{\mathrm{c}}$ \\
Qat $+1000 \times$ PAH & 4 & $19.5 \pm 3.6_{\mathrm{b}}$ & $1.10 \pm 0.33_{\mathrm{b}, \mathrm{c}}$ & $2.21 \pm 0.67_{\mathrm{b}}$ \\
Qat $+10,000 \times$ PAH & 4 & $22.7 \pm 0.2_{\mathrm{a}}$ & $0.581 \pm 0.134_{\mathrm{c}}$ & $0.875 \pm 0.049_{\mathrm{c}}$ \\
Qat $+1000 \times$ TEA & 4 & $17.1 \pm 0.8_{\mathrm{b}}$ & $1.64 \pm 0.35_{\mathrm{a}, \mathrm{b}}$ & $3.04 \pm 0.59_{\mathrm{a}}$ \\
Qat $+100 \times$ QUI & 4 & $17.0 \pm 0.2_{\mathrm{b}}$ & $1.67 \pm 0.19_{\mathrm{a}, \mathrm{b}}$ & $3.47 \pm 0.40_{\mathrm{a}}$ \\
\hline
\end{tabular}

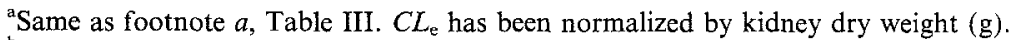

${ }^{b}$ Clearance ratio $(C R)$ was calculated for quinaprilat using the urinary clearance method [Eq. (6)].

Although statistical differences were evident among some of the treatment groups (Tables II and IV), protein binding alterations were probably due to the inherent variability in experimental conditions (e.g., perfusate composition, assay). A competitive displacement of quinapril or quinaprilat by the 
inhibitors is unlikely since, in most cases, the fraction unbound is unchanged or reduced. Regardless, the clearance ratio calculations correct for any differences that may be present during the study conditions.

\section{Metabolic Disposition}

In all rat IPK experiments ( \pm inhibitors), quinapril was not metabolized to any other drug species besides quinaprilat. In addition, no further metabolites of either generated or preformed quinaprilat were found. Thus, these whole organ studies were consistent with the metabolic profile observed from in vitro (19) and in vivo (20) experiments in rats.

\section{DISCUSSION}

Few studies have directly addressed the mechanisms of renal tubular transport for the ACE inhibitors. In an in vivo rat study, Lin et al. (21) demonstrated that probenecid, $\mathrm{p}$-aminohippurate, and quinine had no effect on the renal clearance of lisinopril. Based on this finding and the fact that the drug's clearance ratio was 1.01 (using the urinary clearance method; $\left.C L_{\mathrm{e}} /[f u \cdot G F R]\right)$, the authors concluded that lisinopril was eliminated in the kidney by glomerular filtration alone. In contrast, the concomitant administration of probenecid and p-aminohippurate caused a profound decrease in the clearance ratio of enalaprilat ( 2.72 alone vs. 1.10 in the presence of probenecid vs. 1.24 in the presence of p-aminohippurate; urinary clearance method). These results and the lack of effect by quinine indicated that, unlike lisinopril, enalaprilat was secreted by the organic anion transport system. In a study using isolated red blood cell-perfused rat kidneys, de Lannoy et al. (22) observed that the clearance ratios of enalapril and enalaprilat were approximately 0.5 and unity, respectively (using the urinary clearance method), in the recirculating constant-pressure model. Based on these observations, the authors concluded that while enalapril was renally cleared by a net reabsorption process, enalaprilat was cleared by net filtration. However, the former conclusion is tenuous since this method of analysis did not account for enalapril's significant extent of metabolism within the kidney. In fact, in the presence of intrarenal metabolism it may be inappropriate to designate the "net renal transport process" of a drug (23). Thus, as an alternative method of data analysis, we estimated the clearance ratio of enalapril at 7 to 8 (using the total renal clearance method), a result indicative of extensive net transport across the basolateral membrane of proximal tubular cells. Although clarification of enalapril's renal tubular transport 
could be obtained with the use of known competitive inhibitors of secretory transport, this option was not pursued (22).

Human studies have suggested that many ACE inhibitors, including captopril, enalapril and enalaprilat, and quinapril and quinaprilat, are renally cleared by glomerular filtration and tubular secretion $(1,24,25)$. Further, it appears that these ACE inhibitors are transported via the nonspecific organic acid secretory pathway. As a result, probenecid pretreatment has been shown to significantly reduce the renal clearance of captopril (26) and enalapril and enalaprilat (27), whereas hydrochlorothiazide coadministration resulted in a decrease in the renal clearance of enalaprilat but not enalapril (28). Drug interaction studies with organic cations suggest that these ACE inhibitors do not utilize the nonspecific organic base secretory pathway $(3,4,29,30)$. However, in general, many of the drug interactions reported in humans are difficult to interpret given the lack of renal clearance measurements, the limited number of dose combinations studied for ACE inhibitor \pm transport inhibitor, and the potential effect of urine flow alterations on the renal clearance of ACE inhibitor \pm diuretic. Further, intrarenal metabolism may complicate the interpretation of renal excretion data in humans, as was demonstrated in rat IPK experiments $(6,22)$.

In the present rat IPK studies, it was observed that the clearance ratio of quinapril was substantially reduced in a dose-dependent manner by both probenecid and p-aminohippurate (Table II). As a consequence of this apparent competitive inhibition, perfusate concentrations of quinaprilat were decreased since quinapril's entry into the renal proximal cell was blocked along with its subsequent intrarenal metabolism (Fig. 2). In contrast, tetraethylammonium and quinine did not attenuate the clearance ratio of quinapril. In fact, the quinapril clearance ratio was significantly increased by these substrates, and may reflect an effect on quinapril reabsorption. Although the mechanism by which this effect occurs is unclear at present, it was not due to a urine flow- or $\mathrm{pH}$-dependent reduction in passive reabsorption since these physiological parameters were unchanged in the quinapril \pm tetraethylammonium, quinine treatments (Table II). An alternate hypothesis is that quinapril may be undergoing reabsorption by a carriermediated system (e.g., proton/peptide cotransporter). If so, then the renal cell-to-lumen transport of organic cations across the brush border membrane (via cation/proton exchanger) may have resulted in a less favorable microclimate $\mathrm{pH}$ such that quinapril reabsorption was reduced and its clearance ratio increased. This observation is supported by the fact that quinapril is a tripeptide analog and that other ACE inhibitors have been shown to utilize the peptide transporter in intestine $(31,32)$.

After quinaprilat administration (Table IV), the clearance ratio of quinaprilat was reduced in a dose-dependent manner by both organic acid 
transport inhibitors. Although there was a trend for quinaprilat clearance ratio to decrease when coperfused with tetraethylammonium or quinine, this difference was not statistically significant. It was also found that only $p$ aminohippurate caused a substantial and consistent decrease in the clearance ratio of generated metabolite (Fig. 3). The apparent inability of probenecid (but not p-aminohippurate) to inhibit quinaprilat transport at the brush border membrane cannot be explained by differences in the perfusate concentrations of accumulating metabolite. As shown in Fig. 2, quinaprilat perfusate levels were virtually identical after quinapril plus $100 \times \mu \mathrm{M}$ probenecid vs. quinapril plus $10,000 \times \mu \mathrm{M}$ p-aminohippurate treatments, but their effects differed markedly. An effect of inhibitors on cellular uptake from tubular fluid is also unlikely since in vivo micropuncture studies have demonstrated that quinaprilat reabsorption is minimal $(\leq 10 \%)(33)$. Thus, the data suggest a selective inhibition by probenecid at the basolateral membrane. whereas p-aminohippurate may inhibit at the basolateral and brush border membranes.

In analyzing the temporal aspects of quinaprilat clearance ratio (after dosing quinaprilat), this parameter was observed to be relatively constant for all treatments except that of low dose p-aminohippurate (Fig. 5). To further investigate this phenomenon, the clearance ratio of quinaprilat was evaluated with respect to p-aminohippurate perfusate concentrations. As shown in Fig. 6, perfusate concentrations of p-aminohippurate were sufficiently high during the $10,000 \times \mu \mathrm{M}$ treatment $(>5000 \mu \mathrm{M})$ such that the quinaprilat clearance ratio was diminished but constant over time. In contrast, $\mathrm{p}$-aminohippurate perfusate concentrations fell rapidly during the $1000 \times \mu \mathrm{M}$ treatment $(<5000 \mu \mathrm{M})$ and, as a result, the efficiency of inhibition decreased while the quinaprilat clearance ratio increased with time (i.e., with reduced levels of inhibitor).

Although not specifically addressed, it is possible that quinapril and quinaprilat may interfere with each other at the level of transport. However, this omission does not detract from our conclusion that quinapril and quinaprilat are both transported into and across renal proximal cells by the organic acid secretory pathway. This is so because after dosing quinapril, significant reductions in the clearance ratio of quinapril were observed in the presence of anionic inhibitors (Table II) even though less quinaprilat was being formed (Fig. 2). And after dosing quinaprilat, there is no quinapril present to have an effect.

Quinapril (possessing an amino group, $\mathrm{p} K_{\mathrm{a}} 5.4$ and a carboxyl group, $\mathrm{p} K_{\mathrm{a}} 2.8$ ) and quinaprilat (possessing an amino group, $\mathrm{p} K_{\mathrm{a}}=8.3$ and two carboxyl groups, $\mathrm{p} K_{\mathrm{a}} \mathrm{s} 2.7,4.5$ ) are both amphoteric compounds. At physiological $\mathrm{pH}$, quinapril is completely ionized at its carboxyl group and completely unionized at its amino group; quinaprilat is completely ionized at 


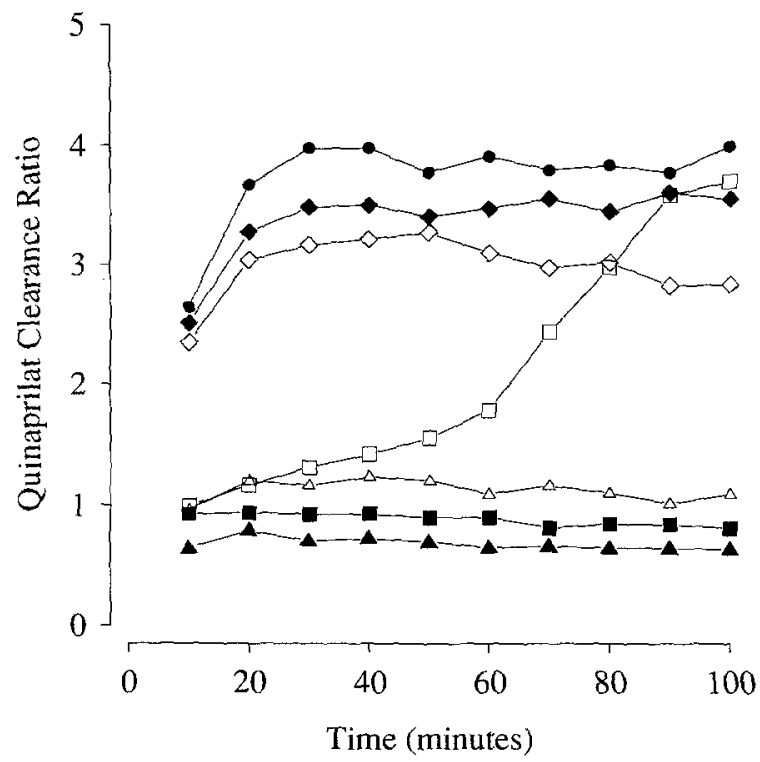

Fig. 5. Clearance ratio-time curves for quinaprilat in the rat IPK after administration of quinaprilat $(2.36 \mu \mathrm{M})$ alone $(\mathbf{0}$, $n=7)$, or when coperfused with probenecid at $100 \times \mu \mathrm{M}(\triangle$, $n=4)$, probenecid at $1000 \times \mu \mathrm{M}(\boldsymbol{\Lambda}, n=4)$, p-aminohippurate at $1000 \times \mu \mathrm{M}(\square, n=4)$, p-aminohippurate at $10,000 \times \mu \mathrm{M}(\mathbf{\square}$, $n=4)$, tetraethylammonium at $1000 \times \mu \mathrm{M}(\diamond, n=4)$, and quinine at $100 \times \mu \mathrm{M}(\diamond, n=4)$. For the sake of clarity, only mean data are shown.

both carboxyl groups and about $90 \%$ ionized at its amino group. Since both quinapril and quinaprilat are anionic in nature, they would be expected to utilize the organic acid transport system of the proximal tubule. This expectation was confirmed experimentally with the use of potent competitive inhibitors of the renal anionic transport system but not by inhibitors of the renal cationic transport system. Mechanistically, it is clear that for organic acid secretion, the active step in transport occurs at the basolateral surface, that negligible transport occurs paracellularly, and that facilitated diffusion is likely at the luminal surface (34). Thus, the anionic inhibitors (probenecid, p-aminohippurate) may block transport of quinapril and quinaprilat into the cell at the basolateral membrane (i.e., active step) and/or transport into the tubular fluid at the brush border membrane (i.e., facilitated step). The likelihood of a specific effect of inhibitors on esterase activity seems remote, and we are unaware of such an occurrence.

Quinapril and quinaprilat were coperfused with high inhibitor concentrations in order to probe their renal tubular transport mechanisms. Plasma 


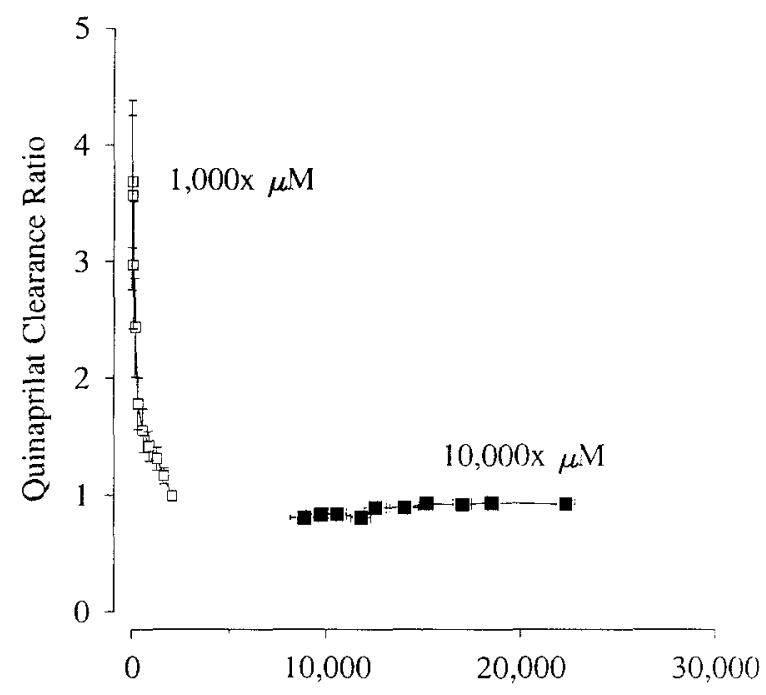

Perfusate p-Aminohippurate Concentration $(\mu \mathrm{M})$

Fig. 6. Relationship between quinaprilat clearance ratio and perfusate concentration of p-aminohippurate in the rat IPK when quinaprilat $(2.36 \mu \mathrm{M})$ was coperfused with p-aminohippurate at $1000 \times \mu \mathrm{M}(\square, n=4)$ and $10,000 \times \mu \mathrm{M}(\boldsymbol{\mathbb { E }}, n=4)$. Data are displayed as mean \pm SEM.

concentrations of probenecid are observed at $700 \mu \mathrm{M}$ which is about 300 times greater than the initial perfusate concentration of ACE inhibitor. Thus, drug is being coperfused with probenecid $(100-1000 \times \mu \mathrm{M})$ at clinically relevant concentrations. Plasma concentrations of $\mathrm{p}$-aminohippurate $(\mathrm{PAH})$ are observed at $3090 \mu \mathrm{M}$ which is about 1300 times greater than the initial perfusate concentration of ACE inhibitor. Thus, drug is being coperfused with $\mathrm{PAH}(1000 \times \mu \mathrm{M})$ at clinically relevant concentrations. $\mathrm{PAH}$, at the higher dose level $(10,000 \times \mu \mathrm{M})$ was necessary because of its rapid elimination from the perfusate with time, thus, effecting its ability to inhibit quinaprilat in a consistent manner (see Figs. 5 and 6 ).

Overall, the inhibition data support our initial studies with quinapril and quinaprilat alone in the rat IPK (6). In this regard, quinapril and quinaprilat are actively secreted by the kidney. Further, quinapril is extensively metabolized by the kidney to quinaprilat, a process coupled to its net tubular transport across the basolateral membrane of proximal tubular cells. Finally, the results demonstrate that the organic anionic secretory system is the primary mechanism by which quinapril and quinaprilat are transported into and across renal proximal cells. 


\section{REFERENCES}

I. J. B. Kostis, J. J. Raia, Jr., E. A. DeFelice, J. A. Barone, and R. G. Deeter. Comparative clinical pharmacology of ACE inhibitors. In J. B. Kostis and E. A. DeFelice (eds.), Angiotensin Converting Enzyme Inhibitors, Alan R. Liss, New York, 1987, pp. 19. 54.

2. R. N. Brogden, P. A. Todd, and E. M. Sorkin. Captopril: An update of its pharmacodynamic and pharmacokinetic properties, and therapeutic use in hypertension and congestive heart failure. Drugs 36:540-600 (1988).

3. P. A. Todd and K. L. Goa. Enalapril: A reappraisal of its pharmacology and therapeutic use in hypertension. Drugs 43:346-381 (1992).

4. A. N. Wadworth and R. N. Brogden. Quinapril: A review of its pharmacological properties, and therapeutic efficacy in cardiovascular disorders. Drugs 41:378-399 (1991).

5. G. H. Williams and E. Braunwald. Hypertensive vascular disease. In E. Braunwald, K. J. Isselbacher, R. G. Petersdorf, J. D. Wilson, J. B. Martin, and A. S. Fauci (eds.), Harrison's Principles of Internal Medicine, 11th ed., McGraw-Hill, New York, 1987, pp. 1024-1037.

6. A. R. Kugler, S. C. Olson, and D. E. Smith. Disposition of quinapril and quinaprilat in the isolated perfused rat kidney. J. Pharmacokin. Biopharm. 23:287-305 (1995).

7. J. M. Nishiitsutsuji-Uwo, B. D. Ross, and H. A. Krebs. Metabolic activities of the isolated perfused rat kidney. Biochem. J. 103:852-862 (1967).

8. R. H. Bowman. The perfused rat kidney. Meth. Enzymol. 39:3-11 (1975).

9. F. H. Epstein, J. T. Brosnan, J. D. Tange, and B. D. Ross. Improved function with amino acids in the isolated perfused kidney, Am. J. Physiol. 243:F284-F292 (1982).

10. H. A. Krebs and K. Henseleit. Untersunchugen uber die harnstoffbildung im tierkorper. Z. Physiol. Chem. 210:33-36 (1932).

11. A. R. Kugler, S. C. Olson, and D. E. Smith. Determination of quinapril and quinaprilat by high-performance liquid chromatography with radiochemical detection, coupled to liquid scintillation spectrometry. J. Chromatog. B. 666:360-367 (1995).

12. T. Prueksaritanont, M. L. Chen, and W. L. Chiou. Simple and micro high-performance liquid chromatographic method for simultaneous determination of p-aminohippuric acid and iothalamate in biological fluids. J. Chromatog. 306:89-97 (1984).

13. B. D. Ross. The isolated perfused rat kidney. Clin. Sci. Mol. Med. 55:513-521 (1978).

14. T. Maack. Physiological evaluation of the isolated perfused rat kidney. Am. J. Physiol. 238:F71-F78 (1980).

15. I. Bekersky. Use of the isolated perfused kidney as a tool in drug disposition studies. Drug Metab. Rev. 14:931-960 (1983).

16. C. A. Rodriguez and D. E. Smith. Influence of the unbound concentration of cefonicid on its renal elimination in isolated perfused rat kidneys. Antimicrob. Agents Chemother. 35:2395-2400 (1991).

17. C. A. Rodríguez and D. E. Smith. Influence of angiotensin II-induced alterations in renal flow on excretion of cefonicid in isolated perfused rat kidneys. Antimicrob. Agents Chemother. 36:616-619 (1992).

18. D. E. Smith, S. Guillard, and C. A. Rodríguez. Effect of angiotensin II-induced changes in perfusion flow rate on chlorothiazide transport in the isolated perfused rat kidney. J. Pharmacokin. Biopharm. 20:195-207 (1992).

19. A. R. Kugler, S. C. Olson, and R. A. Jordan. In vitro quinapril metabolism in rat, dog, monkey, and human liver preparations. Pharm. Res. 8(Suppl.):S-239 (1991).

20. H. R. Kaplan, D. G. Taylor, S. C. Olson, and L. K. Andrews. Quinapril: A preclinical review of the pharmacology, pharmacokinetics, and toxicology. Angiology 40:335-350 (1989).

21. J. H. Lin, I. W. Chen, E. H. Ulm, and D. E. Duggan. Differential renal handling of angiotensin-converting enzyme inhibitors enalaprilat and lisinopril in rats. Drug Metab. Dispos. 16:392-396 (1988).

22. I. A. M. de Lannoy, R. Nespeca, and K. S. Pang. Renal handling of enalapril and enalaprilat: Studies in the isolated red blood cell-perfused rat kidney. J. Pharmacol. Exp. Ther. 251:1211-1222 (1989). 
23. D. E. Smith and A. R. Kugler. Influence of intrarenal metabolism on the analysis of renal drug transport mechanisms. J. Pharm. Sci. 88:1519-20 (1994).

24. S. K. Mujais, A. Quintanilla, M. Zahid, K. Koch, W. Shaw, and T. Gibson. Renal handling of enalaprilat. Am. J. Kidney Dis. 19:121-125 (1992).

25. S. C. Olson, A. M. Horvath, B. M. Michniewicz, A. J. Sedman, W. A. Colburn, and P. G. Welling. The clinical pharmacokinetics of quinapril. Angiology 40:351-359 (1989).

26. S. M. Singhvi, K. L. Duchin, D. A. Willard, D. N. McKinstry, and B. H. Migdalof. Renal handling of captopril: Effect of probenecid. Clin. Pharmacol. Ther. 32:182-189 (1982).

27. F. H. Noormohamed, W. R. McNabb, and A. F. Lant. Pharmacokinetic and pharmacodynamic actions of enalapril in humans: Effect of probenecid pretreatment. J. Pharmacol. Exp. Ther. 253:362-368 (1990).

28. K. Weisser, J. Schloos, S. Jakob, W. Mühlberg, D. Platt, and E. Mutschler. The influence of hydrochlorothiazide on the pharmacokinetics of enalapril in elderly patients. Eur. J. Clin. Pharmacol. 43:173-177 (1992).

29. K. L. Duchin, D. N. McKinstry, A. I. Cohen, and B. H. Migdalof. Pharmacokinetics of captopril in healthy subjects and in patients with cardiovascular diseases. Clin. Pharmacokin. 14:241-259 (1988).

30. V Vertes and R. Haynie. Comparative pharmacokinetics of captopril, enalapril, and quinapril. Am. J. Cardiol. 69:8C-16C (1992).

31. V. Ganapathy, M. Brandsch, and F. H. Leibach. Intestinal transport of amino acids and peptides. In L. R. Johnson (ed.), Physiology of the Gastrointestinal Tract, Raven Press, New York, 1994, pp. 1773-1794.

32. G. L. Amidon and H. J. Lee. Absorption of peptide and peptidomimetic drugs. Ann. Rev. Pharmacol. Toxicol. 34:321-341 (1994).

33. D. E. Smith, A. R. Kugler, and J. B. Schnermann. Reabsorption and metabolism of quinapril and quinaprilat in rat kidney: In vivo micropuncture studies. J. Pharm. Sci. 84:1147-1150 (1995).

34. D. C. Brater, P.P. Sokol, S. D. Hall, and T. D. McKinney. Disposition and dose requirements of drugs in renal insufficiency. In D. W. Seldin and G. Giebisch (eds.), Dridey Physiology and Pathophysiology, 2nd ed., Raven Press.- New York, 1992, pp $3671-3695$. 